\title{
Influence of the Addition of Selected Spices on Sensory Quality and Biological Activity of Honey
}

\author{
Aleksandra Wilczyńska, ${ }^{1}$ Joanna Newerli-Guz, ${ }^{1}$ and Piotr Szweda ${ }^{2}$ \\ ${ }^{1}$ Department of Commodity Science and Quality Management, Gdynia Maritime University, ul. Morska 81-87, 81-225 Gdynia, Poland \\ ${ }^{2}$ Department of Pharmaceutical Technology and Biochemistry, Gdańsk University of Technology, ul. Narutowicza 11/12, \\ 80-233 Gdańsk, Poland
}

Correspondence should be addressed to Aleksandra Wilczyńska; a.wilczynska@wpit.am.gdynia.pl

Received 13 July 2016; Revised 16 January 2017; Accepted 15 February 2017; Published 5 March 2017

Academic Editor: Giuseppe Zeppa

Copyright (c) 2017 Aleksandra Wilczyńska et al. This is an open access article distributed under the Creative Commons Attribution License, which permits unrestricted use, distribution, and reproduction in any medium, provided the original work is properly cited.

\begin{abstract}
Bee honey is nutritious and has numerous health benefits, but its taste is for many people too bland. Honey with addition of spices could be important to the food industry as a functional product with positive health image and interesting taste. Such product would definitely meet health-driven consumers' expectations. Therefore, the aim of this study was to evaluate the effect of addition of selected spices on sensory, antimicrobial, and antioxidant properties of honey. Results showed that the addition of spices significantly affected the taste and the smell of honey $(p<0,05)$ and that honey with the cinnamon was the most desired and easily accepted product by the consumers. The addition of spices had no significant effect on texture and appearance. All tested samples showed the ability to inhibit the growth of bacteria and, contrary to the assumptions, the addition of spices did not cause an increase of antimicrobial activity. The results also showed that the kind and amount of added spice significantly affected the antioxidant activity: ability to scavenge free radicals and total phenolics content. The highest antioxidant activity revealed the honey with cinnamon and the lowest revealed the honey with cardamom addition.
\end{abstract}

\section{Introduction}

Honey is a natural sweetener that, in addition to being well accepted by consumers taste qualities, has valuable nutritional and health benefits. It is a rich source of energy and has many antimicrobial properties. Honey may be used for treatment of many diseases such as colds, skin wounds, and various gastrointestinal diseases [1-5]. It is also a well-known source of antioxidant compounds such as phenolic acids and flavonoids, which play an important role among the components influencing the health properties of honey. Antioxidant capacity of honey depends mainly on its biological and geographical origin [6-11]. The processing, storing, and handling of honey may change its antioxidant activity [12, 13].

Spices are food ingredients, popular in every cuisine; they can be used in food products, not only because of their flavoring properties, taste, aroma, and color. The popular spices are cinnamon, cardamom, and ginger which are characterized by intense taste and aroma and have been used in human diet worldwide for a long time. Their flavoring application and impact on other product features are important. In addition to their aromatic contribution to foods, these spices have been reported to have biological activity. They are rich sources of natural antioxidants and also exhibit anti-inflammatory and antimicrobial potentials [14-18]. Antioxidant activity of these spices is generally associated with the levels of phenolic compounds; however, there are some other characteristics, for example, gingerol and zingerone in ginger [19].

Recently, due to increasing interest in finding functional foodstuffs, products based on honey, containing added nuts, herbs, or spices, have appeared in the European market. These products could combine the properties of honey and added substances. Therefore, the objectives of this study were to evaluate the sensory and biological properties of different types of honey with spices and the impact of the addition of cardamom, cinnamon, and ginger to the honey on sensory quality and on its total phenolic content, radical scavenging against DPPH radicals and antibacterial activity. 
Furthermore, the effect of different concentrations of added spices on parameters mentioned above was examined.

\section{Materials and Methods}

2.1. Plant Material and Sample Preparation. Dried spices, cardamom, cinnamon, and ginger, were obtained from the Pomeranian market. Five packages of every investigated spice were taken from market according to PN-ISO 948 [20] and then milled according to PN-ISO 2825 [21]. Samples of honey with $0.5 \%, 1 \%$, and $2 \%$ addition of these spices were prepared. The base honey was multifloral honey, collected in June 2014, obtained directly from traditional apiary from Pomeranian region. The honey was characterized by pale colour, solid, coarsely granulated consistency, delicate sweet taste and floral aroma. Honey samples with spices were were stored in room temperature in the dark before analysis.

2.2. Chemicals. All the chemicals and reagents used were of analytical grade. DPPH (1,1 diphenyl-2-picrylhydrazyl), Folin-Ciocalteu reagent, gallic acid, and HPLC grade methanol were obtained from Fluka, Germany. Potassium persulfate and sodium carbonate were purchased from POCH, Poland. PBS, Mueller-Hinton Agar (MHA), and Mueller-Hinton Broth (MHB2) were purchased from Sigma-Aldrich, Germany.

\subsection{Methods}

2.3.1. Sensory Evaluation. Samples of honey with $0.5 \%, 1 \%$, and $2 \%$ addition of spices were evaluated by taste panel. Taste, aroma, texture, colour, and appearance were evaluated. International standards based on ISO recommendation were used for unification of sensory evaluation [22]. The assessments were marked on the 5-point structured, unipolar scale.

The sensory characteristics of honey with varying addition of spices and the impact of its addition of taste features on consumers' acceptance were evaluated by using Quantitative Descriptive Analysis (QDA). The QDA method is often applied for detailed description of the sensory characteristics of a product. In this method, as assumption it is accepted that sensory quality is not a single attribute but it is a complex of many descriptors which can be individually estimated by a panel [23].

Attribute descriptors for evaluation of honey with spices samples were developed by 10 panelists who were selected from a large pool of candidates according to their ability to discriminate differences in sensory properties among honey samples. Panelists were staff and students from Gdynia Marine University who regularly participated in sensory analysis and had experience in profiling other food products. Among the panelists were 6 woman and 4 men, 5 persons aged $21-35$, and 5 persons aged $36-50$ years. The panelists were trained over three sessions for descriptive sensory analysis using product and ingredients references. Descriptors' terminology was developed by panelists with the panel leader help. The descriptors chosen by more than 3 panelists were used for preparation of final questionnaire. Chosen taste descriptors were: spicy, bitter, resin, pungent, sweet, insipid, and total palatability. Descriptors were quantified on a 10 point scale, from 0 (attribute not present) to 10 (attribute extremely strong). Panelists evaluated products at the same time but in separation in order to reduce interaction between them.

2.3.2. Antimicrobial Activity. Microbiological investigation of honey samples with spices was carried out immediately after preparation. Antimicrobial activity was specified as minimal inhibitory concentration (MIC). Four reference strains of bacteria, S. aureus PCM 2051, S. epidermidis PCM 2118, P. aeruginosa ATCC 27853, and E. coli K12, were used for determination of antimicrobial activity of the honeys. All strains of bacteria were grown on Mueller-Hinton Agar (MHA) plates. The assay of antibacterial activity of honeys was performed on the basis of Clinical and Laboratory Standards Institute (CLSI) guidelines [24, 25] with slight modifications [26]. Briefly, overnight bacterial cultures grown on MHA plates were suspended in PBS ( $\mathrm{pH} 7.4)$ to the cell density of approximately $1-5 \times 10^{8} \mathrm{CFU} / \mathrm{mL}$ and in the next step diluted in Mueller-Hinton Broth (MHB2) at a ratio of $1: 150 \mathrm{v} / \mathrm{v}$ to the final cells concentrations of approximately $1.5 \times 10^{6} \mathrm{CFU} / \mathrm{mL}$.

The samples of honey were diluted in twofold concentrated MHB2 medium at a volume ratio $1: 1$. The obtained $50.00 \%(\mathrm{v} / \mathrm{v})$ solutions of honeys were sterilized by filtration through $0.22 \mu \mathrm{m}, \varnothing 25 \mathrm{~mm}$ PTFE membrane (Millipore, USA). Using the obtained solution, a series of twofold dilutions of the honeys in the range of $1.56-50.00 \%(\mathrm{v} / \mathrm{v})$ were prepared in a 96-well plate using MHB2 medium. Subsequently, the honey solutions in the wells were inoculated with an equal volume of suspension of bacterial cells, prepared as described previously. The final concentrations of inoculated honeys ranged from 0.78 to $25.00 \%$ (v/v). Additionally positive control of the growth of tested strain and control of the medium sterility were performed. The plates were incubated for 24 hours at $37^{\circ} \mathrm{C}$. After the incubation, the MIC values of the tested agents were determined by measuring the absorbance at $531 \mathrm{~nm}$ using a Victor ${ }^{3}$ microplate reader (Perkin Elmer, USA). The lowest concentration of the honey that caused inhibition of growth equal to or higher than $90 \%$ of growth control was taken as the MIC value. The MIC assay for each tested strain and honey sample was performed three times.

2.3.3. Antioxidant Activity. The scavenging activity against 1,1-diphenyl-2-picrylhydrazyl hydrate (DPPH) radical was estimated according to the procedure described by Turkmen et al. [12] with some modifications. The $2 \mathrm{~g}$ of honey sample was dissolved in $10 \mathrm{ml}$ of distillated water, centrifuged, and filtered by paper filter. Then, $0,75 \mathrm{ml}$ of the solution was mixed with $2,25 \mathrm{ml}$ of $0,1 \mathrm{mM}$ methanol solution of DPPH 1,1-diphenyl-2-picrylhydrazyl. The control test was made with distillated water in place of honey solution. The reaction mixtures were vortex-mixed well and left in room temperature in the dark for incubation for $15 \mathrm{~min}$. Absorbance was measured at $\lambda=517 \mathrm{~nm}$ against methanol, using UVVIS spectrophotometer Unicam. Antioxidant activity was 
TABLE 1: The results of the sensory score of honey with spices.

\begin{tabular}{lccccc}
\hline \multirow{2}{*}{ Type of spice } & \multirow{2}{*}{ Amount of spice [\%] } & \multicolumn{3}{c}{ Sensory score [mean ${ }^{*} \pm$ SD] } \\
& & Taste & Aroma & Texture & Colour/appearance \\
\hline Control & - & $2.41 \pm 0,65$ & $4.00 \pm 1,08$ & $3.51 \pm 0,84$ & $4,52 \pm 0,76$ \\
\hline \multirow{3}{*}{ Cardamom } & 0.5 & $2.96^{\mathrm{a}, \mathrm{c}} \pm 0.81$ & $1.94^{\mathrm{c}} \pm 0.73$ & $3.27^{\mathrm{a}} \pm 1.00$ & $3.90^{\mathrm{a}} \pm 1.02$ \\
& 1 & $3.91^{\mathrm{a}, \mathrm{b}} \pm 0.99$ & $2.88^{\mathrm{a}, \mathrm{c}, \mathrm{d}} \pm 1.24$ & $3.65^{\mathrm{a}} \pm 1.00$ & $3.81^{\mathrm{a}} \pm 1.01$ \\
\hline \multirow{3}{*}{ Cinnamon } & 2 & $4.22^{\mathrm{a}, \mathrm{b}} \pm 0.85$ & $3.59^{\mathrm{a}, \mathrm{b}} \pm 1.39$ & $2.72^{\mathrm{a}} \pm 1.26$ & $3.14^{\mathrm{a}} \pm 1.12$ \\
& 0.5 & $3.06^{\mathrm{a}, \mathrm{c}} \pm 0.87$ & $2.21^{\mathrm{c}, \mathrm{d}} \pm 1.09$ & $4.18^{\mathrm{a}} \pm 1.04$ & $4.22^{\mathrm{a}} \pm 0.82$ \\
& 1 & $3.49^{\mathrm{a}, \mathrm{b}, \mathrm{c}} \pm 0.09$ & $3.13^{\mathrm{a}, \mathrm{b}, \mathrm{c}, \mathrm{d}} \pm 1.01$ & $4.16^{\mathrm{a}} \pm 1.14$ & $4.31^{\mathrm{a}} \pm 0.79$ \\
Ginger & 2 & $4.45^{\mathrm{b}} \pm 0.89$ & $4.19^{\mathrm{a}, \mathrm{b}, \mathrm{d}} \pm 0.64$ & $3.95^{\mathrm{a}} \pm 1.23$ & $3.78^{\mathrm{a}} \pm 1.03$ \\
& 0.5 & $2.20^{\mathrm{b}, \mathrm{c}} \pm 1.36$ & $3.44^{\mathrm{a}, \mathrm{b}} \pm 1.57$ & $3.74^{\mathrm{a}} \pm 1.16$ & $4.02^{\mathrm{a}} \pm 0.92$ \\
& 1 & $3.28^{\mathrm{a}, \mathrm{b}, \mathrm{c}} \pm 1.08$ & $3.97^{\mathrm{a}, \mathrm{b}} \pm 1.13$ & $3.75^{\mathrm{a}} \pm 1.22$ & $3.86^{\mathrm{a}} \pm 0.93$ \\
\hline
\end{tabular}

*5-point structured, unipolar acceptance scale was used in taste panel (1: dislike very much, 5: like very much). Reference letters (a, b, c, and d) indicate homogeneous groups, distinguished on the basis of the post hoc analysis (Tukey's test).

Source: own research.

expressed as a percent of inhibition of DPPH radical and calculated from the equation:

$$
\mathrm{AA}[\%]=\frac{\left(\mathrm{Abs}_{\text {contr } \left.-\mathrm{Abs}_{\text {sample }}\right)}\right.}{\mathrm{Abs}_{\text {contr }}} \text {. }
$$

To determine the total phenolic content of honeys, the method of Meda [27] was adapted. Honey solutions with concentration of $1 \mathrm{~g} / 10 \mathrm{ml}$ were centrifuged and filtered by paper filter. After that, $0,5 \mathrm{ml}$ obtained solutions were mixed with $2,5 \mathrm{ml} \mathrm{0,2} \mathrm{N}$ solution of Folin-Ciocalteu reagent and $2 \mathrm{ml}$ of sodium carbonate solution ( $75 \mathrm{~g} / \mathrm{l}, \mathrm{POCH}$, Poland) was added. After incubation in the dark and room temperature for $2 \mathrm{~h}$, absorbance of the reaction mixture was measured at $\lambda=760 \mathrm{~nm}$ using UV-VIS spectrophotometer Unicam. The standard curve was produced for gallic acid within the concentration range from 0 to $200 \mathrm{mg} / \mathrm{l}$. The total phenolic content was expressed as gallic acid equivalents in $\mathrm{mg} / 100 \mathrm{~g}$ of honey sample (mg GAE/100 g). The analyses were made in duplicate.

2.4. Statistical Analysis. Results were presented as the mean and standard deviation. To assess the impact of the type and quantity of spices on the evaluated parameters, the oneway and two-way analysis of variance (ANOVA) were used. Statistical hypotheses were verified at a significance level of $p$ values $<0,05$. Calculations were performed with statistical software package Statistica 10.0 (StatSoft Inc., Tulsa, USA).

\section{Results and Discussion}

In this study, honey samples with addition of 3 different spices were evaluated for taste, aroma, texture, and colour/appearance. Results of sensory analysis of investigated honey samples are shown in Table 1 . The mean values for the taste and texture of honey with spices were generally higher than the scores of control honey sample, while for the aroma and colour they were lower. The investigated honeys differed significantly in taste and aroma $(p<0,05)$. In most cases the acceptance of taste and aroma increased simultaneously with the increase in amount of spices, while the addition of major quantities of spices caused a decrease of acceptance of texture and colour. All tested sensory parameters for honey with $2 \%$ cinnamon was rated the highest, and honey with $0,5 \%$ cardamom obtained the lowest score. The taste and aroma of honey with cinnamon gained the highest rating. However, statistical analysis showed that only the kind of added spice $(F=6,54, p=0,00)$ had a significant effect on the acceptability of the taste, whereas the kind and quantity $(F=$ $8,45, p=0,00)$ had effect on the acceptance of aroma. These factors neither affected the acceptance of the consistency nor the color of investigated honey samples.

Due to statistically significant effect of the addition of spices on taste of the samples, QDA analysis for those discriminates was performed. The major sensory taste descriptors and results are presented in Figure 1. Top-perceptible taste was the sweetness. The addition of spices resulted in the increase of taste intensity: spicy, bitter, resin, and pungent and the decrease of intensity of sweet taste. Statistical analysis showed that addition of all types of spices had significant influence only on spicy taste assessment. Cardamom addition significantly affected bitter and resin taste, and the ginger addition pungent and tart taste. Overall palatability of honey with $2 \%$ cinnamon was highly accepted. Addition of cardamom to honey did not affect the overall palatability of the tested samples. The products containing cardamom and cinnamon investigated by Illupapalayam et al. were also highly accepted by consumers [28].

Table 2 shows the results of minimal inhibitory concentration (MIC) of honey inhibiting the growth of bacteria from the group: E. coli, P. aeruginosa, S. epidermidis, and S. aureus.

As for the antibacterial activity of base honey on the different bacterial strains, it was observed that honey solution with a concentration of $12.5 \%$ inhibits the growth of all the tested bacteria. In case of $S$. aureus, the concentration of $6.25 \%$ had an inhibitory effect.

Therefore, it could be said that base honey was characterized by high antibacterial activity, higher than that reported 

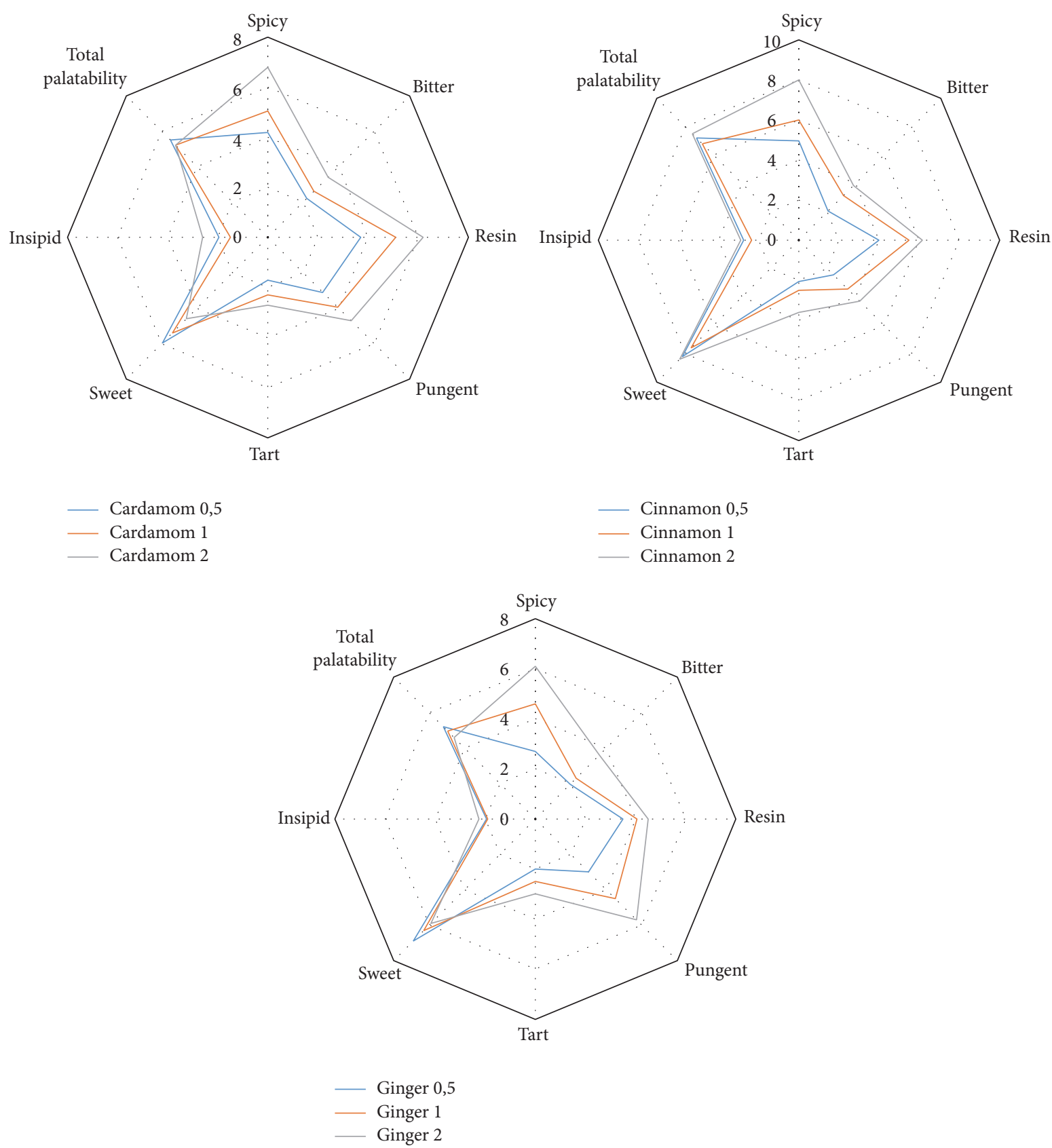

Figure 1: The results of the taste attributes of honey with spices (scale 0-10). Source: own research.

by Basualdo et al., who found that the majority of honeys inhibited the growth of bacteria at concentration of $50 \%$ [29]. The addition of cardamom and ginger had no effect on antibacterial activity; however, the addition of cinnamon reduced it considerably. Both honey and spices are supposed to have an antimicrobial effect; it can therefore be expected that the addition of spices enhances antimicrobial activity of honey. Unfortunately, our study showed that the addition of spices, especially cinnamon, rather reduced this activity. Probably some phytochemicals from honey and spices acted antagonistically and reduced each other's influence on microorganisms.
Figures 2 and 3 show the results of evaluation of total phenolics content (TP) and antioxidant activity (AA DPPH) in the investigated honey samples.

Average level of phenolics TP in base honey was at $43 \mathrm{mg}$ GAE/100 g and antioxidant capacity (AA DPPH) at $56 \%$. These results were comparable with earlier findings of Wilczyńska [10] and similar to results obtained by other authors for multifloral honeys [30]. The addition of spices in different quantities caused changes of antioxidant activity of investigated honeys. In general, the addition of cinnamon increased antioxidant activity of honey. The more the cinnamon was added, the greater the phenolics content and 
TABLE 2: Antimicrobial activity of investigated honey samples with spices addition.

\begin{tabular}{|c|c|c|c|c|c|}
\hline \multicolumn{2}{|c|}{ Sample } & \multicolumn{4}{|c|}{ MIC [\% w/v] } \\
\hline Kind of spice & Amount of spice [\%] & E. coli & P. aeruginosa & S. epidermidis & S. aureus \\
\hline 0 & 0 & 12.5 & 12.5 & 12.5 & 6.25 \\
\hline \multirow{3}{*}{ Cinnamon } & 0.5 & 12.5 & 25 & 12.5 & 12.5 \\
\hline & 1 & 25 & 25 & 25 & 25 \\
\hline & 2 & 25 & 25 & 25 & 25 \\
\hline \multirow{3}{*}{ Ginger } & 0.5 & 12.5 & 12.5 & 12.5 & 6.25 \\
\hline & 1 & 12.5 & 12.5 & 12.5 & 6.25 \\
\hline & 2 & 12.5 & 12.5 & 12.5 & 6.25 \\
\hline \multirow{3}{*}{ Cardamom } & 0.5 & 12.5 & 12.5 & 12.5 & 6.25 \\
\hline & 1 & 12.5 & 12.5 & 12.5 & 6.25 \\
\hline & 2 & 12.5 & 12.5 & 12.5 & 6.25 \\
\hline
\end{tabular}

Source: own research.

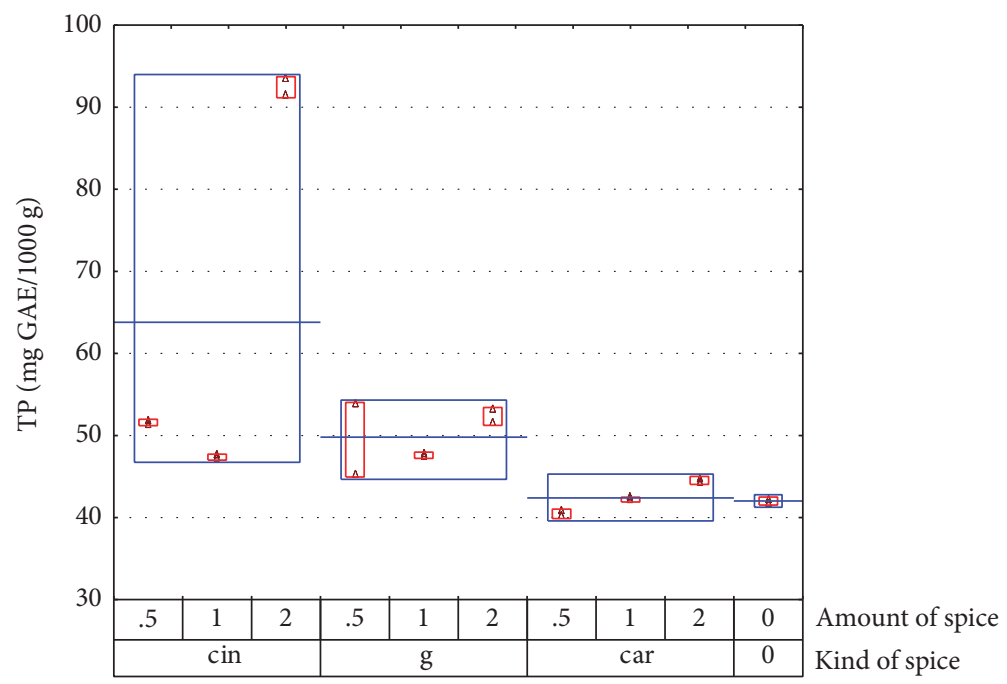

FIGURE 2: Average TP in honey samples with addition of different quantities of different spices (cin: cinnamon, g: ginger, and car: cardamom). Source: own research.

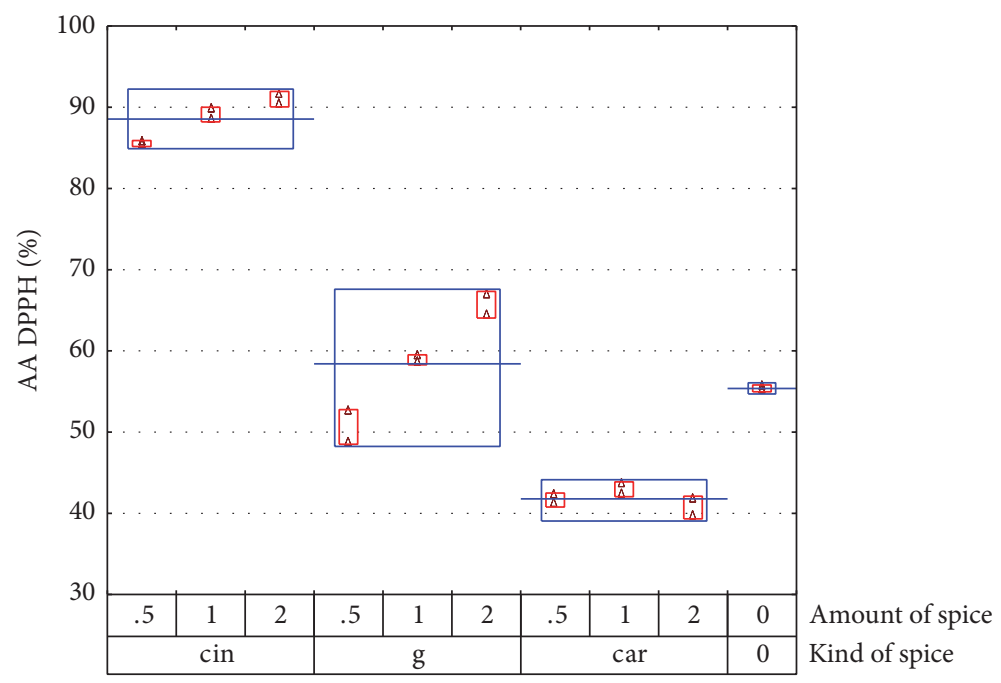

FIGURE 3: Average AA DPPH in honey samples with addition of different quantities of different spices (cin: cinnamon, g: ginger, and car: cardamom). Source: own research. 
TABLE 3: The effect of selected factors on antioxidant activity of honey, in the multivariate tests of significance.

\begin{tabular}{lccc}
\hline Parameter & Factor & The value of the $F$-statistic & The probability $P$ \\
\hline \multirow{2}{*}{ TP } & Type of spice & 3,33 & 0,0426 \\
& Amount & 2,4126 & 0,1047 \\
& Type and amount of spice & 87,18054 & 0,0000 \\
AA DPPH & Type of spice & 130,4234 & 0,0000 \\
& Amount & 0,1819 & 0,9071 \\
& Type and amount of spice & 19,49703 & 0,0001 \\
\hline
\end{tabular}

Source: own research.

radical scavenging activity were reached. Ginger acted similar to cinnamon, although its influence on the TP and AA DPPH values was lower.

The addition of cardamom had the least beneficial effect on antioxidant activity of honey. It practically did not change the total phenolics content but decreased the scavenging activity. According to Przygodzka et al. [16] and Nanasombat and Wimuttigosol [15], cinnamon had the highest antioxidant activity, whereas ginger and cardamom were the spices with low antioxidant potential. The statistical analysis showed that the amount, type of added spice, and combination of those factors affected the antioxidant activity of investigated honey (Table 3).

\section{Conclusions}

Mixture effect can occur simply because foods are not isolated pure chemicals but complex combination of thousands of compounds with potential impact on the senses of taste, smell, and texture [31]. In conclusion, addition of spices influenced the sensory score and biological activity of the investigated samples of honey. There were statistically important differences in taste and aroma of the honey samples. Taste of the honey with spices was better accepted by consumers than control honey. The selected spices in this study effected especially on spicy taste. Sensory quality of investigated honeys was affected by amount of spices. Analyzed honey samples with spices had lower antimicrobial activity than control sample, but the addition of spices increased the antioxidant activity, especially the addition of cinnamon. The present study is just the first approach to ascertain that addition of spices to honey had positive effect on sensory and biological properties of these mixtures.

\section{Additional Points}

Practical Applications. Adding spices to a popular base product such as honey creates basis for many practical implications. Immediate attention is drawn to the positive attributes of both the honey and the spices and a novel product that can diversify and enrich the offer of honey products already present in the market. Improving the flavor and providing potential health benefits with an enhancement of antioxidant capacity are expected to enhance consumers' acceptance of honey. This unique combination of honey and spices is expected to boost the number of honey consumers.

\section{Competing Interests}

The authors declare that there is no conflict of interests regarding the publication of this paper.

\section{References}

[1] P. C. Molan, "The antibacterial activity of honey," Bee World, vol. 73, no. 1, pp. 5-28, 1992.

[2] P. C. Molan, "The antibacterial activity of honey: 2. Variation in the potency of the antibacterial activity," Bee World, vol. 73, no. 2, pp. 59-76, 1992.

[3] R. J. Weston, "The contribution of catalase and other natural products to the antibacterial activity of honey: a review," Food Chemistry, vol. 71, no. 2, pp. 235-239, 2000.

[4] P. J. Taormina, B. A. Niemira, and L. R. Beuchat, "Inhibitory activity of honey against foodborne pathogens as influenced by the presence of hydrogen peroxide and level of antioxidant power," International Journal of Food Microbiology, vol. 69, no. 3, pp. 217-225, 2001.

[5] P. E. Lusby, A. L. Coombes, and J. M. Wilkinson, "Bactericidal activity of different honeys against pathogenic bacteria," Archives of Medical Research, vol. 36, no. 5, pp. 464-467, 2005.

[6] M. Al-Mamary, A. Al-Meeri, and M. Al-Habori, "Antioxidant activities and total phenolics of different types of honey," Nutrition Research, vol. 22, no. 9, pp. 1041-1047, 2002.

[7] N. Gheldof, X.-H. Wang, and N. J. Engeseth, "Identification and quantification of antioxidant components of honeys from various floral sources," Journal of Agricultural and Food Chemistry, vol. 50, no. 21, pp. 5870-5877, 2002.

[8] G. Beretta, P. Granata, M. Ferrero, M. Orioli, and R. M. Facino, "Standardization of antioxidant properties of honey by a combination of spectrophotometric/fluorimetric assays and chemometrics," Analytica Chimica Acta, vol. 533, no. 2, pp. 185191, 2005.

[9] A. Alves, A. Ramos, M. M. Gonçalves, M. Bernardo, and B. Mendes, "Antioxidant activity, quality parameters and mineral content of Portuguese monofloral honeys," Journal of Food Composition and Analysis, vol. 30, no. 2, pp. 130-138, 2013.

[10] A. Wilczyńska, "Phenolic content and antioxidant activity of different types of polish honey-a short report," Polish Journal of Food and Nutrition Sciences, vol. 60, no. 4, pp. 309-313, 2010.

[11] P. M. Kuś, F. Congiu, D. Teper, Z. Sroka, I. Jerković, and C. I. G. Tuberoso, "Antioxidant activity, color characteristics, total phenol content and general HPLC fingerprints of six Polish unifloral honey types," LWT-Food Science and Technology, vol. 55, no. 1, pp. 124-130, 2014. 
[12] N. Turkmen, F. Sari, E. S. Poyrazoglu, and Y. S. Velioglu, "Effects of prolonged heating on antioxidant activity and colour of honey," Food Chemistry, vol. 95, no. 4, pp. 653-657, 2006.

[13] A. Wilczyńska, "Effect of filtration on colour, antioxidant activity and total phenolics of honey," LWT-Food Science and Technology, vol. 57, no. 2, pp. 767-774, 2014.

[14] M. Mueller, S. Hobiger, and A. Jungbauer, "Anti-inflammatory activity of extracts from fruits, herbs and spices," Food Chemistry, vol. 122, no. 4, pp. 987-996, 2010.

[15] S. Nanasombat and P. Wimuttigosol, "Antimicrobial and antioxidant activity of spice essential oils," Food Science and Biotechnology, vol. 20, no. 1, pp. 45-53, 2011.

[16] M. Przygodzka, D. Zielińska, Z. Ciesarová, K. Kukurová, and H. Zieliński, "Comparison of methods for evaluation of the antioxidant capacity and phenolic compounds in common spices," LWT-Food Science and Technology, vol. 58, no. 2, pp. 321-326, 2014.

[17] A. Durak, U. Gawlik-Dziki, and I. Kowlska, "Coffee with ginger -interactions of biologically active phytochemicals in the model system," Food Chemistry, vol. 166, pp. 261-269, 2015.

[18] G. Mazzarrino, A. Paparella, C. Chaves-López et al., "Salmonella enterica and Listeria monocytogenes inactivation dynamics after treatment with selected essential oils," Food Control, vol. 50, pp. 794-803, 2015.

[19] K. V. Peter, Handbook of Herbs and Spices, CRS, Press Woodhead Publishing, Cambridge, UK, 2000.

[20] PN-ISO 948:2009 Spices and condiments-Sampling.

[21] PN-ISO 2825 Herbs and spices, preparation of the ground sample for analysis.

[22] ISO 8586:2012 Sensory analysis-General guidance for the selection, training and monitoring of assessors and expert sensory assessors.

[23] M. Meilgaard, G. Vance Civille, and B. Thomas Carr, Sensory Evaluation Techniques, CRC Press, Boca Raton, Fla, USA, 3rd edition, 1999.

[24] CLSI, "Methods for antimicrobial dilution and disk susceptibility testing of infrequently isolated or fastidious bacteria; proposes guideline," CLSI Document M45-P, Clinical and Laboratory Standards Institute, Philadelphia, Pa, USA, 2005.

[25] CLSI, Performance Standards for Antimicrobial Susceptibility Testing; Seventeenth Informational Supplement, CLSI Document M100-S17, Clinical Laboratory Standard Institute, 2007.

[26] P. M. Kuś, P. Szweda, I. Jerković, and C. I. G. Tuberoso, "Activity of Polish unifloral honeys against pathogenic bacteria and its correlation with colour, phenolic content, antioxidant capacity and other parameters," Letters in Applied Microbiology, vol. 62, no. 3, pp. 269-276, 2016.

[27] A. Meda, C. E. Lamien, M. Romito, J. Millogo, and O. G. Nacoulma, "Determination of the total phenolic, flavonoid and proline contents in Burkina Fasan honey, as well as their radical scavenging activity," Food Chemistry, vol. 91, no. 3, pp. 571-577, 2005.

[28] V. V. Illupapalayam, S. C. Smith, and S. Gamlath, "Consumer acceptability and antioxidant potential of probiotic-yogurt with spices," LWT - Food Science and Technology, vol. 55, no. 1, pp. 255-262, 2014.

[29] C. Basualdo, V. Sgroy, M. S. Finola, and J. M. Marioli, “Comparison of the antibacterial activity of honey from different provenance against bacteria usually isolated from skin wounds," Veterinary Microbiology, vol. 124, no. 3-4, pp. 375-381, 2007.
[30] E. Majewska and J. Trzanek, "Antioxidant activity of multiflower honey and other bee products," Bromatologia i Chemia Toksykologiczna, vol. 4, pp. 1089-1094, 2009.

[31] H. T. Lawless, "Sensory combination in the meal," in Dimensions of the Meal: The Science, Culture, Business and Art of Eating, pp. 92-116, AN Aspen Publication, Gaithersburg, Md, USA, 2000. 

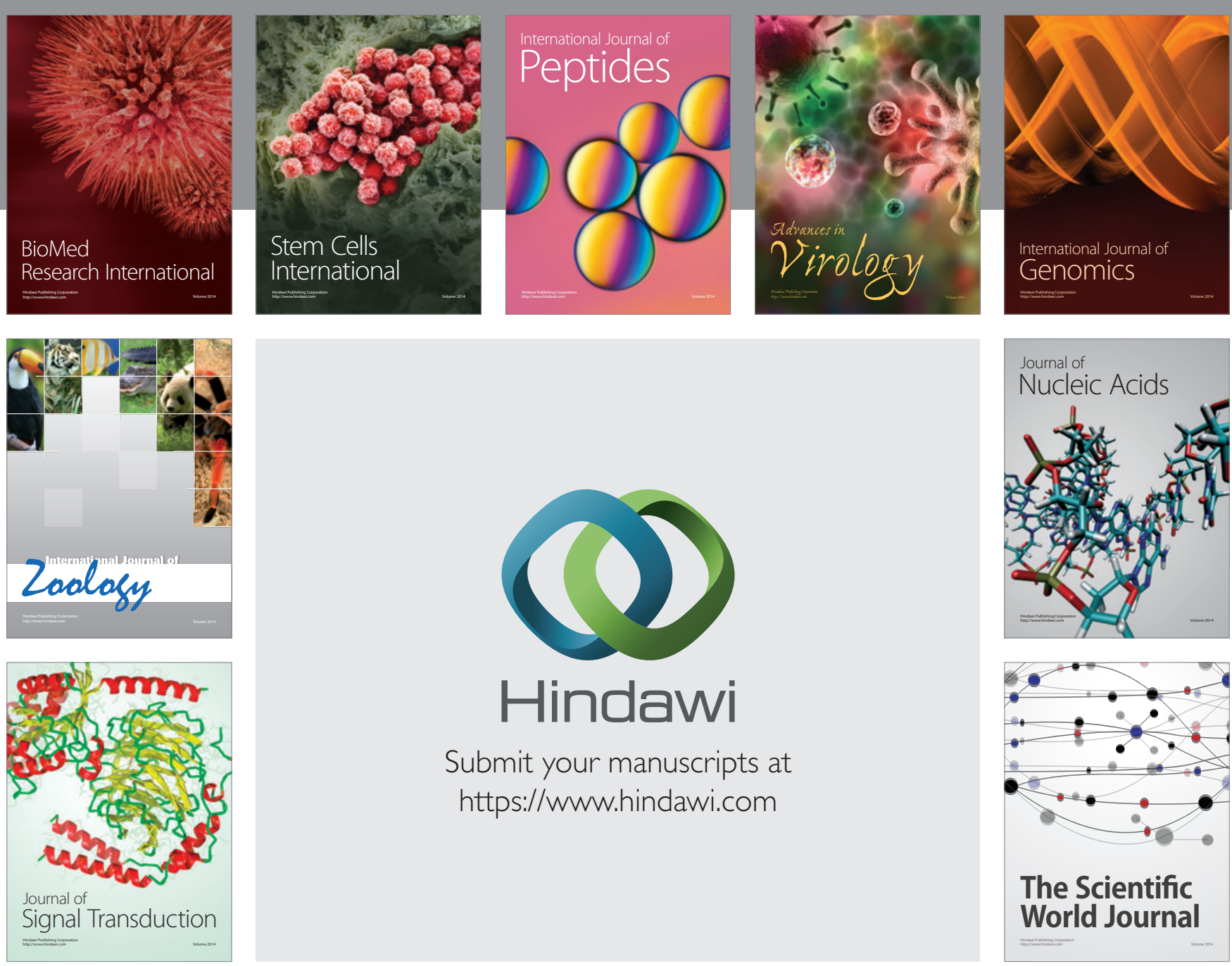

Submit your manuscripts at

https://www.hindawi.com
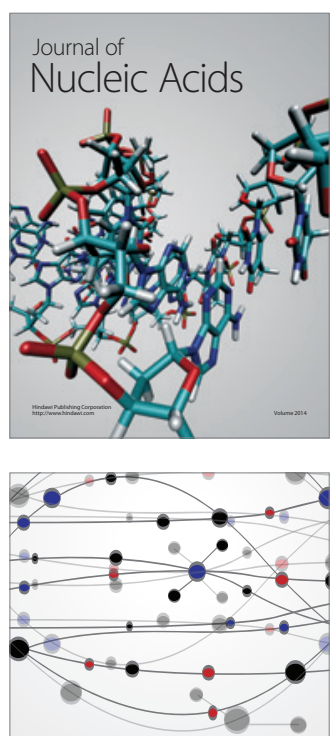

The Scientific World Journal
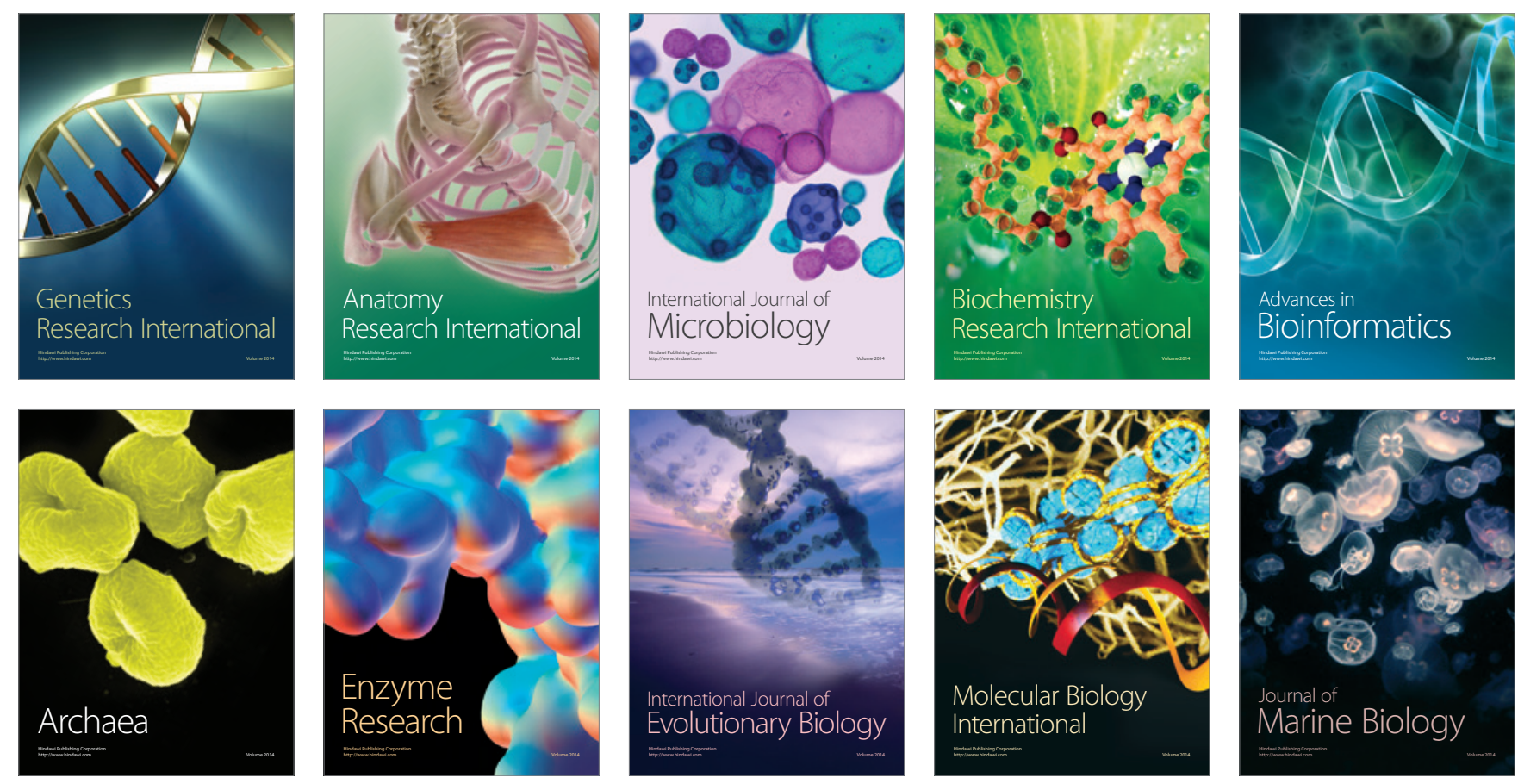